\title{
AG COATED PA-BASED ELECTRO-CONDUCTIVE KNITTED FABRICS FOR HEAT GENERATION IN COMPRESSION SUPPORTS
}

\author{
Md. Reazuddin Repon ${ }^{1}$, Daiva Mikučionienè ${ }^{1, *}$, Ilze Baltina², Juris Blūms ${ }^{3}$, Ginta Laureckiene ${ }^{1}$ \\ 1 Kaunas University of Technology, Faculty of Mechanical Engineering and Design, Department of Production Engineering, Studentu 56, LT-51424, \\ Kaunas, Lithuania \\ 2 Riga Technical University, Faculty of Materials Science and Applied Chemistry, Institute of Design Technologies, Kipsalas 6, LV-1048, Riga, Latvia \\ 3 Riga Technical University, Technical Physics Institute, Kipsalas 6, LV-1048, Riga, Latvia \\ ${ }^{*}$ Corresponding author. E-mail: daiva.mikucioniene@ktu.lt
}

\begin{abstract}
:
This work deals with the electrically conductive textiles for heat generation in orthopedic compression supports. This study aimed to develop compression knitted structures with integrated electro-conductive yarns and investigate their heat generation characteristics and temperature changes during the time and under stretch which is required to generate compression. Combined half-Milano rib structured knitted fabrics were made by using silver (Ag) coated PA yarn of linear density of 66 tex and 235 tex, respectively. Six variants of specimens were developed by using different amount of electro-conductive yarns in a pattern repeat. It was found that stretch negatively influences temperature values as well as time in which the required temperature is reached. Therefore, the final wearing conditions have to be summed up during the designing of compression orthopedic heated supports.
\end{abstract}

\section{Keywords:}

Conductive textiles, heat generation, knitted structure, compression

\section{Introduction}

Electrically conductive textile is part of smart textiles that includes conductive fibers, yarns, fabrics, and final products made from them [1]. Conductive fabrics can be made of naturally conductive yarns or specially treated materials to impart conductivity using different techniques. In all techniques, metals particles, conductive fillers or conductive polymers are used to fabricate electrically conductive fabrics [2]. Conductive fabrics have received greater attention for its antistatic applications, antimicrobial and anti-odor purposes, electromagnetic interference shielding, infrared absorption or protective clothing in explosive areas, etc. [3-6]. An important application area of electrically conductive fabrics is its usage in heating purposes. Heating fabrics have been used in numerous and varied fields such as sports, leisure, automotive, household use, industrial or technical purposes such as motorbike gloves, heating pads, leisure garments, and sport garments, medical fields such as electrotherapy treatment, orthopedic supports, medical blanket for maintaining patient's body temperature, strain sensors, and motion capturing devices [7, 8].

There are two ways to produce heated textiles. One way is to produce a textile fabric and then integrating electronic components with it, and the other is to produce an electroconductive yarn with electronic features and then producing textile with that yarn [9-13]. The thermo-mechanical behavior of textile heating fabrics based on silver coated polymeric yarns has been studied and it was found that the fabric knitted with silver yarn along with elastomeric yarn can generate heat to warm up the body [14]. It was also found that interlock structure knitted with silver coated yarn has better heating performance in comparison to plain and rib structures, as the interlock structure allowed more current to pass through it at relatively lower voltages.

Many research works focused about construction and properties and behavior of knitted compression structures used for orthopedic supports can be found in a literature [15-17], however, the literatures focused on investigations in the field of electro-conductive knitted fabrics used for heat generation in orthopedic compression supports are lacking. Knitted orthopedic supports are assigned to compression garments and the level of compression is governed by the garment size as well as the ability of fabric stretching. Fabric for compression garments is usually designed with a stretchable structure and contains elastomeric yarns to achieve highly stretchable and appropriate compression [18]. In most cases, combined knitting patterns with elastomeric inlay-yarns are used for the manufacturing of orthopedic compression products. Further, it is known that all supplementary rigid elements used in orthopedic supports for medical and wear comfort purposes 
have significant influence on the compression generated by the support [17].

It is a known fact that heat therapy helps to relax stiff joints and reduces pain [19]. Due to age-related loss of active muscle mass, the temperature of the skin and deep muscle decreases. Decrease in body temperature can profoundly change motor function and performance [20]. However, there is a lack of investigations in the field of the heated compression supports used for orthopedic therapy in the literature. The temperature required for the joints therapy is around $40-45^{\circ} \mathrm{C}$. It means that this temperature has to be reached and kept constant for a particular time. Moreover, the heating of the orthopedic support has to be solved without additional rigid elements to avoid changes in the support compression.

Therefore, the aim of this research was (1) to develop compression knitted structures for orthopedic compression supports with integrated electro-conductive silver coated polyamide yarns and (2) to investigate their heat generation characteristics and temperature changes under elongation which is required for compression generation. The measurements were performed during the time $(1 \mathrm{~h})$ to determine when the heating process becomes stable.

\section{Materials and methods}

Six different knitted specimens based on the electro-conductive yarn amount and distribution in the knitted structure were developed and compared according to the heat generation. The ELITEX (silver coated polyamide) yarns of 66 tex and 235 tex linear density (Imbut $\mathrm{GmbH}$, Germany) were used as conductive yarns. These two variants of linear density were chosen as possible marginal values suitable for plated structure in combination with selected yarns for ordinary elastomeric structure used in orthopedic supports. The specimens were knitted on a flat double needle-bed 14E gauge knitting machine CMS 340TC-L (STOLL, Germany) in which elastomeric inlayyarn is inserted into every course of the knitted structure with a combined half-Milano rib structure. The half-Milano rib structure was chosen in order to position electro-conductive yarns on one surface; therefore, conductive yarns were used only in the
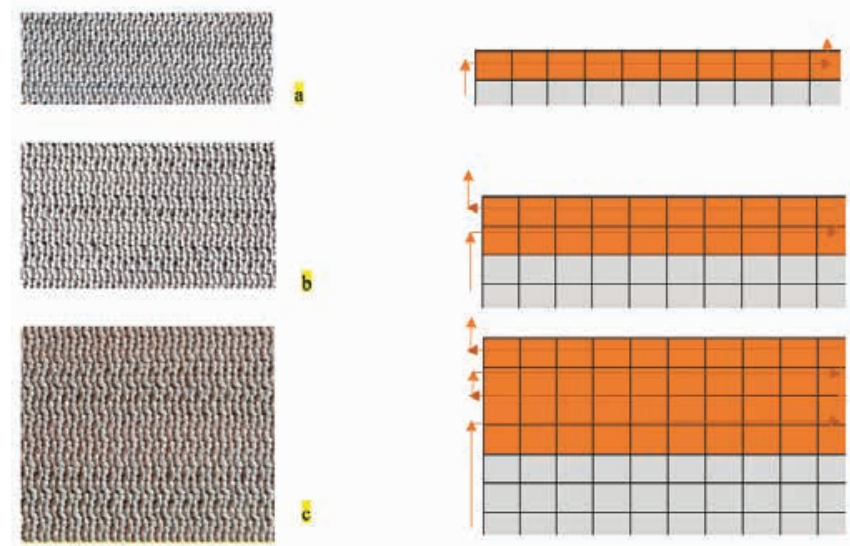

Figure 1. Images and principle scheme of conductive yarn layout on the technical back side of a specimen ( $\square$ courses with conductive yarn, $\square$ courses without conductive yarn, $\longrightarrow$ path of conductive yarn): (a) - EFL1 and EFH1; (b) - EFL2, and EFH2; (c) - EFL3 and EFH3.

single jersey courses of the pattern. Moreover, the conductive yarn was plated by the PA6.6 (Polyamide) yarn to secure it from the mechanical abrasion. Images and principle schemes of the conductive yarn layout in three variants of knitted structure are presented in Figure 1. The principle schemes of the developed knitting structures are presented in Figure 2. The combination of 7.8 tex x4 PA6.6 and 4.4 tex PU (polyurethane), double covered by 4.4 tex PA6.6, yarns were used as the ground yarn for formation of the rib courses. Silver coated PA yarns with linear density of 66 tex (in EFL samples) and 235 tex (in $\mathrm{EFH}$ samples) were used in plated single jersey courses as a ground yarns, while 7.8 tex $x 4$ PA6.6 yarn was used in these courses as a plated yarn. For elastomeric inlay yarn, 114.5 tex PU double covered by 7.8 tex x4 PA6.6 was used and laid in each second course (i.e. in rib structure courses of the halfMilano pattern). The main characteristics of electro-conductive knitted specimens are presented in Table 1. Average values of loop length, loop density, and area density were calculated from 10 measurements taken for each one.

The fluke 561 HVACPro infrared thermometer was used to determine the surface temperature from measuring the amount of infrared energy radiated by target's surface.

Table 1. Characteristics of electro-conductive knitted fabrics.

\begin{tabular}{|c|c|c|c|c|c|c|c|}
\hline \multirow[t]{3}{*}{$\begin{array}{l}\text { Sample } \\
\text { code }\end{array}$} & \multirow[t]{3}{*}{$\begin{array}{l}\text { Area density } \\
\qquad\left(\mathrm{g} / \mathrm{m}^{2}\right)\end{array}$} & \multicolumn{4}{|c|}{ Wale $P_{v}$ and course $P_{h}$ density $\left(\mathrm{cm}^{-1}\right)$} & \multirow[t]{3}{*}{$\begin{array}{l}\text { Average loop } \\
\text { length } I(\mathrm{~mm})\end{array}$} & \multirow[t]{3}{*}{$\begin{array}{c}\text { Sample area } \\
\qquad\left(\mathrm{m}^{2}\right)\end{array}$} \\
\hline & & \multicolumn{2}{|c|}{ Technical face side } & \multicolumn{2}{|c|}{ Technical back side } & & \\
\hline & & $P_{v}$ & $P_{h}$ & $P_{v}$ & $P_{h}$ & & \\
\hline EFL1 & $326 \pm 2$ & $6.7 \pm 0.2$ & $12.7 \pm 0.3$ & $6.7 \pm 0.2$ & $6.7 \pm 0.2$ & $8.2 \pm 0.3$ & 0.022 \\
\hline EFL2 & $324 \pm 2$ & $6.9 \pm 0.2$ & $12.7 \pm 0.3$ & $6.7 \pm 0.2$ & $6.7 \pm 0.2$ & $8.2 \pm 0.2$ & 0.022 \\
\hline EFL3 & $325 \pm 2$ & $6.7 \pm 0.2$ & $12.9 \pm 0.2$ & $6.7 \pm 0.2$ & $6.7 \pm 0.2$ & $8.2 \pm 0.3$ & 0.022 \\
\hline $\mathrm{EFH} 1$ & $351 \pm 2$ & $6.7 \pm 0.2$ & $13.3 \pm 0.3$ & $6.9 \pm 0.2$ & $6.3 \pm 0.2$ & $8.1 \pm 0.2$ & 0.022 \\
\hline $\mathrm{EFH} 2$ & $349 \pm 2$ & $6.9 \pm 0.2$ & $13.3 \pm 0.3$ & $6.9 \pm 0.2$ & $6.3 \pm 0.2$ & $8.1 \pm 0.2$ & 0.022 \\
\hline $\mathrm{EFH3}$ & $350 \pm 2$ & $6.7 \pm 0.2$ & $13.0 \pm 0.3$ & $6.9 \pm 0.2$ & $6.3 \pm 0.2$ & $8.1 \pm 0.3$ & 0.022 \\
\hline
\end{tabular}



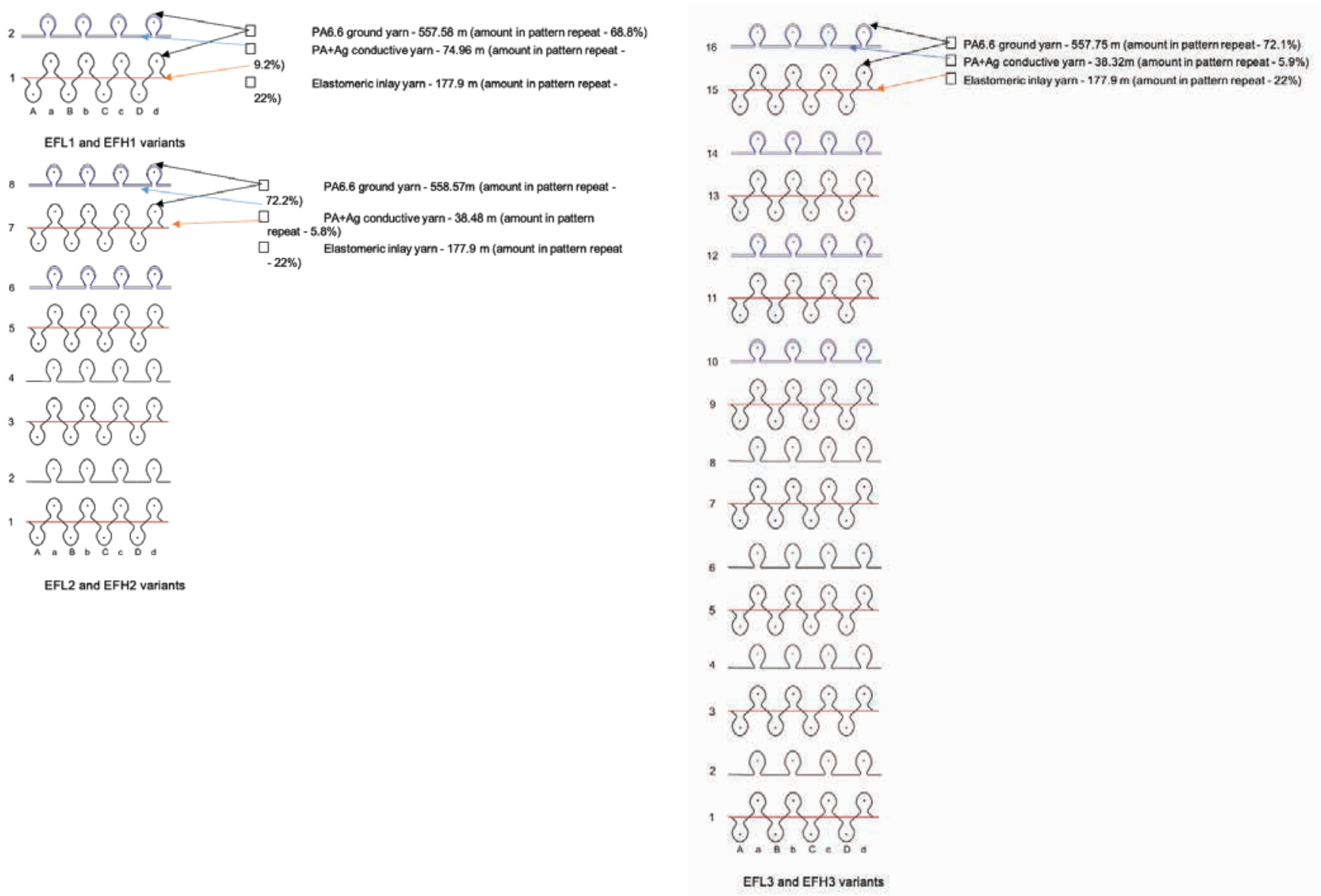

Figure 2. Knitting structures: three variants of combined half-Milano rib with elastomeric inlay-yarn in each rib course and PA + Ag conductive yarn in plated single jersey courses (laid in different pattern repeat).

Infrared specifications of the thermometer were: temperature measurement range $-40-550^{\circ} \mathrm{C}$; spectral range $8-14 \mu \mathrm{m}$; accuracy $\pm 1^{\circ} \mathrm{C}$; and response time (95\%) $500 \mathrm{~ms}$. The single point laser was used on the thermometer and the wavelength was 630-670 nm. The FLIR DM285, True RMS digital multimeter, and thermal imager were used for thermal imaging of the specimens. The absolute error of all measurements of temperature did not exceed $1^{\circ} \mathrm{C}$.

Properties of conductive fibers, their inter-connection within a fabric and to external circuitry, and the geometry of the fabric altogether contribute to the electrical resistance of a fabric specimen (Figure 3). Surface resistance of the fabric specimens were measured by using Signstek UNI-T UT71D

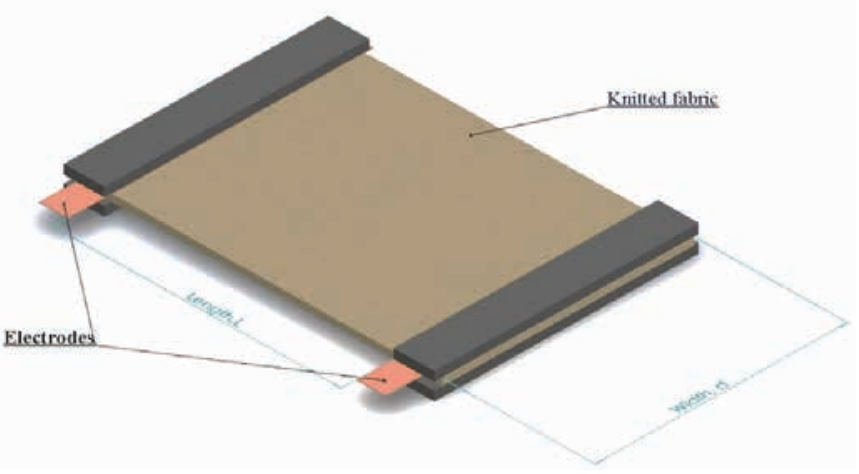

Figure 3. Principle of fabric surface resistance measurement.
True RMS multimeter. For current dependence on voltage measurement, two copper plates of precise sizes were placed on the two opposite edges of the specimen. Electrode plates were connected with variable DC power supply. The applied voltage was progressively increased and observed values of current across the fabric were noted from ammeter.

An Instron (model 2519-107) tensile testing machine was used for stretching the specimens in transversal direction (along courses). This transversal direction of stretch was selected because compression supports are worn stretched in the same direction to generate compression. Knitted samples were strained at fixed extension. The stretch values $(10 \%, 15 \%$, and $20 \%$ ) were chosen to reach limited and average values of compression which corresponds to the 1st compression class according to German Standard RAL-GZ-387/1:2008. It is a light compression which can be applied every day along with heating for prophylactic to reduce pain and protect joins. Compression of the tested samples was calculated by the Laplace formula:

$$
P=\frac{2 \cdot \pi \cdot F}{S}
$$

where $P$ is the pressure in $\mathrm{Pa}, F$ is the tensile force in $\mathrm{N}$, and $S$ is the area of the specimen in $\mathrm{m}^{2}$.

Tensile force values (coefficient of variation that did not exceed $7 \%$ ) and compression generated at selected stretch are presented in Table 2. 
Table 2. Tensile force and compression generated at selected stretch values.

\begin{tabular}{|c|c|c|c|c|c|c|}
\hline \multirow{2}{*}{$\begin{array}{c}\text { Sample } \\
\text { code }\end{array}$} & \multicolumn{3}{|c|}{ Tensile force (N) } & \multicolumn{3}{|c|}{ Compression $(\mathrm{Pa})$} \\
\hline & $10 \%$ & $15 \%$ & $20 \%$ & $10 \%$ & $15 \%$ & $20 \%$ \\
\hline EFL1 & & & & & & \\
\hline $\begin{array}{l}\text { EFL2 } \\
\text { EFL3 }\end{array}$ & 5.21 & 6.70 & 7.93 & 1487.2 & 1912.5 & 2264.6 \\
\hline $\mathrm{EFH} 1$ & & & & & & \\
\hline $\begin{array}{l}\mathrm{EFH} 2 \\
\mathrm{EFH} 3\end{array}$ & 5.35 & 7.02 & 8.25 & 1527.3 & 2003.9 & 2426.3 \\
\hline
\end{tabular}

Temperature was measured after every $10 \mathrm{~s}$ during the first minute of observation, and after every $20 \mathrm{~s}$ starting from the first minute till the end of experiment, i.e. $10 \mathrm{~min}$ (600 s). Average values were calculated from four elementary measurements. Coefficient of variation did not exceed $17 \%$.

All experiments were carried out in a standard atmosphere for testing according to Standard LST EN ISO 139:2005.

\section{Results and discussion}

\subsection{Voltage-current ( $\mathrm{V}-\mathrm{I})$ characteristics}

Resistance, $R_{s}(\Omega)$, is the ratio of DC voltage $(V)$ to the current $\left(I_{s}\right)$ flowing between two electrodes of specified configuration that are in contact with the same side of the materials (see in Figure 3). Resistance values of prepared different specimens are presented in Figure 4.

Resistance increases progressively with the decrease in amount of the conductive yarn in the specimen (see Figure 4). Fabrics with lower linear density of the electro-conductive yarn showed higher surface resistance in comparison to the fabrics with the high linear density (2.5 times higher) of the electro-conductive yarn. When using higher linear density (235 tex) silver coated PA conductive yarn, different distribution of courses with electro-conductive yarn in the knitting pattern (EFH2 and EFH3) does not have influence on the surface resistance. But the difference appeared in specimens EFL2 and EFL3. The results indicate that both the linear density of conductive yarn and knitting structure influence the fabric surface resistance.

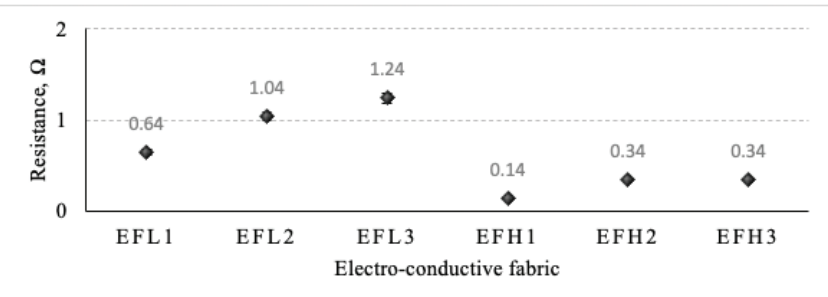

Figure 4. Resistance of electro-conductive fabrics.
The $V-I$ characteristics of investigated electro-conductive fabrics are presented in Figures 5 and 6 . In order to find the quantity of current generated by each knitted specimen at particular voltage, different voltage levels were selected. The quantity of current is very important to reach required temperature. For orthopedic supports used for pain reduction in joints, at least a temperature of $40^{\circ} \mathrm{C}$ has to be reached [19]. It can be seen from the presented results that all fabrics show the linear current dependence on the voltage applied at the low voltage range.

The current values of the specimens EFL1 and EFH1 at particular voltage are found to be significantly higher when compared to the EFL2, EFL3, and EFH2, EFH3. This is because of higher amount of conductive yarns in the knitted structure lower surface resistance. This research showed an interesting tendency: some difference in current is observed between samples knitted with the relatively same amount of the conductive yarn in the fabric but different distribution of courses knitted with conductive yarn and without it, especially at higher voltage.

\subsection{Voltage-temperature (V-T) characteristics}

The electro-conductive fabrics were tested for their voltagetemperature $(V-T)$ characteristics by applying a range of $D C$ voltage. The voltage was applied from $0.5 \mathrm{~V}$ and continuously increased till $40^{\circ} \mathrm{C}$ is reached. Measurements of temperature on the surface of knitted specimens were performed at $10 \mathrm{~s}$ intervals of voltage application in the duration of $1 \mathrm{~min}$. The results are presented in Figures 7 and 8 . This behavior was investigated to show the heat generation behavior with the time. Dependence of the temperature on the voltage applied has exponential character in all time intervals of observation (coefficient of determination $R^{2}$ vary in the ranges $0.81-0.98$ ). It was found that the temperature of $40^{\circ} \mathrm{C}$ of EFL1 specimen was

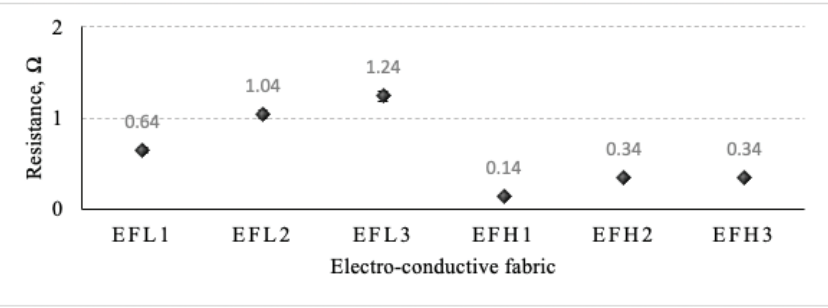

Figure 5. Voltage-current dependence of EFL1, EFL2, and EFL3 structured electro-conductive fabrics.

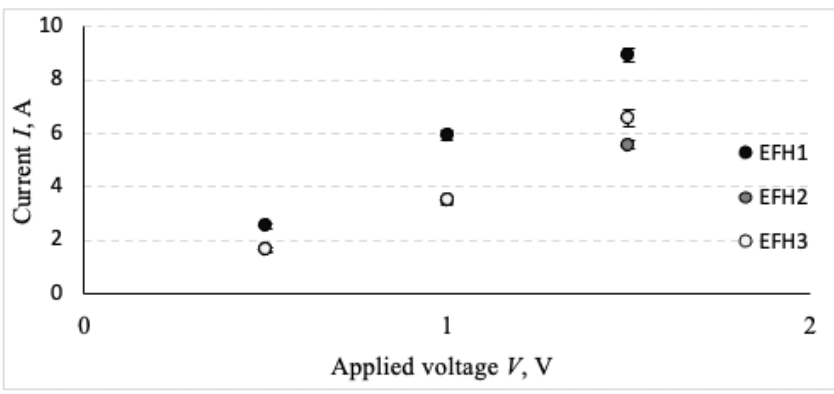

Figure 6. Voltage-current dependence of EFH1, EFH2, and EFH3 structured electro-conductive fabrics. 

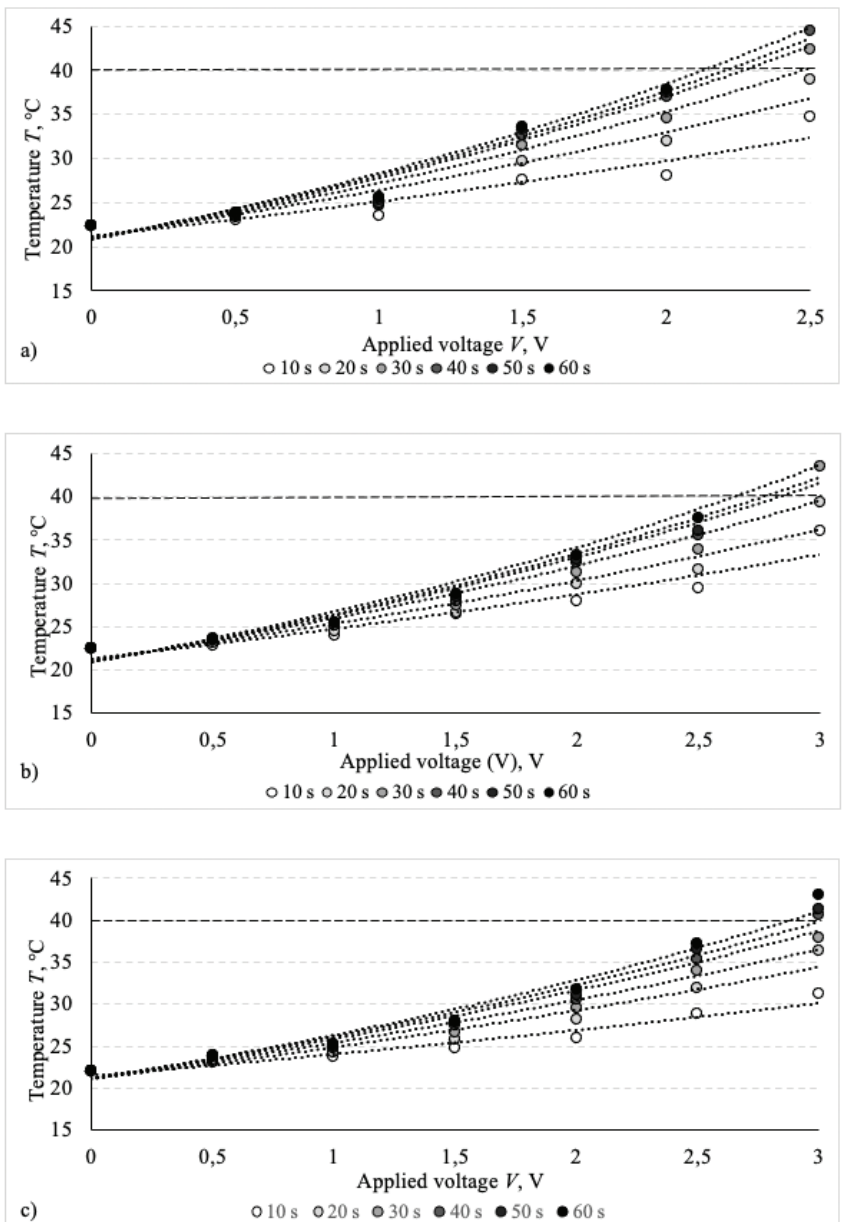

Figure 7. Voltage-temperature characteristics of EFL1 (a), EFL2 (b) and EFL3 (c) structured electro-conductive fabrics.

reached by applying $2.5 \mathrm{~V}$ energy source, while for EFL2 and EFL3 3.0 V voltage was needed to reach this temperature. For all EFH group samples, a power of $1.5 \mathrm{~V}$ was enough to reach the required temperature.

The obtained results demonstrate the dynamics of the temperature changes on the surface of specimens during the time, especially at the higher values of the voltage applied (Figures 7 and 8). The higher voltage generates more current and in turn generates more energy which is released as heat leading to rise in the temperature in the electro-conductive fabric surface. For orthopedic supports, the target temperature is $40^{\circ} \mathrm{C}$ and more (usually up to $45-46^{\circ} \mathrm{C}$ ). It is important that the increase of temperature during the time of higher voltage is also significantly higher, especially for EFL group fabrics with higher surface resistance. By applying voltage of $1 \mathrm{~V}$, temperature on the surface of EFL group knits during $50 \mathrm{~s}$ (from 10th s till 60 th $\mathrm{s}$ ) increased in the range of $2.4-3.7^{\circ} \mathrm{C}$ (depending on the knitting pattern, i.e. distribution of the conductive yarn in the pattern) and when $2.5 \mathrm{~V}$ was applied, the temperature during the same time increased in the range $12-14^{\circ} \mathrm{C}$ degrees. For EFH group knits, the increase of the temperature during $50 \mathrm{~s}$ at $0.5 \mathrm{~V}$ voltage was $2.6-3.0^{\circ} \mathrm{C}$, while at $1.5 \mathrm{~V}$ voltage - it is $15.0-19.5^{\circ} \mathrm{C}$ (depending on the knitting pattern).
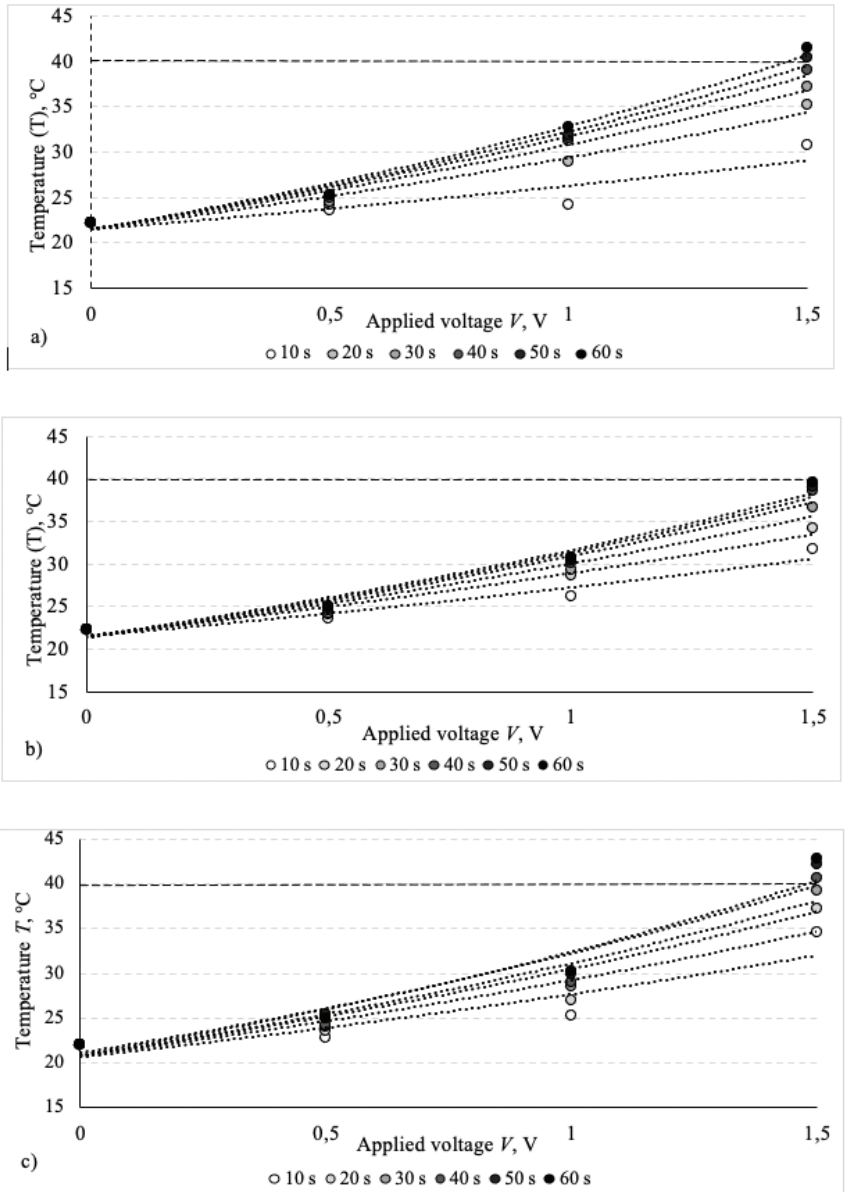

Figure 8. Voltage-temperature characteristics of EFH1 (a), EFH2 (b), and $\mathrm{EFH} 3$ (c) structured electro-conductive fabrics.

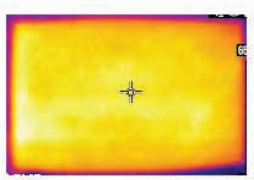

EFL1

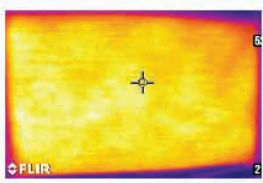

EFH1

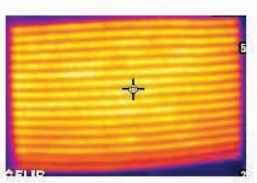

EFL2

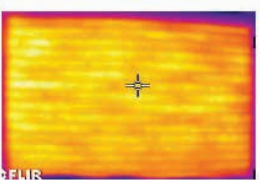

$\mathrm{EFH} 2$

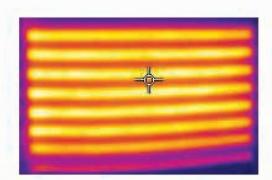

EFL3

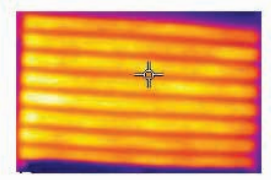

EFH3
Figure 9. Thermal images of fabrics after $10 \mathrm{~min}$ at $1.5 \mathrm{~V}$.

The influence of knitting pattern, i.e., amount of the conductive yarn used in the knitting pattern as well as its distribution in the pattern, is clearly demonstrated in Figure 9, where yellow color indicates the highest temperature $\left(40-45^{\circ} \mathrm{C}\right)$ while the blue color indicates the lowest temperature $\left(26^{\circ} \mathrm{C}\right)$. In this figure, thermal images of the fabrics surface when the power of $1.5 \mathrm{~V}$ is used are presented.

Thermal images visually demonstrate that the highest temperature is reached on the surface of the EFL1 and EFH1, in which conductive yarns are knitted in each second course of the knit (see in Figure 2). The appearance of temperature unevenness on the surface of the knitted structures EFL2, EFL3 
and EFH2, EFH3 is due to the larger distance between courses with the conductive yarn and without it. And this unevenness is higher for the fabrics with lower linear density of the conductive yarn. As it can be seen from the thermal image of EFH2, this structure achieves very good evenness of the surface heating despite the amount of the conductive yarn is two times lower compared to the EFH1. The experimental results also showed the difference in temperature between the edges and the center of heating surface. This scenario was due to the loss of heat by radiation and air convection in edges compared to the center position.

It has to be taken into account that when applying higher voltage (to reach the required temperature), dynamic of the temperature changes during the time is quite slow and this process has to be analyzed with longer period of observation. The target scenario is to reach a required stable surface temperature. Therefore, as the next step of this research, temperature changes on the surface of the newly developed compression knits were investigated in the interval of $600 \mathrm{~s}$ (10 min).

\subsection{Time-temperature (t-T) characteristics}

DC voltage was applied on the electro-conductive surface and required time allowed to heat up. The surface temperature of the fabric was measured at the fixed voltage level for every 10 $\mathrm{s}$ during the first minute of observation, and then for every $20 \mathrm{~s}$ starting from the first minute till the end of experiment, i.e., $10 \mathrm{~min}(600 \mathrm{~s})$. The obtained results are presented in Figures 10 and 11. It can be seen in the presented results that temperature increases quickly at first, but after approximately $90 \mathrm{~s}$ the increase in temperature becomes very slow and within 20-30 s it reaches the constant value while the heating process becomes stable. The behavior of the temperature is reasonable, and with increase in the temperature, the heat lost by radiation and air convection start to increasing and then the balance between heat generated and heat lost is achieved finally.

The required temperature $\left(40^{\circ} \mathrm{C}\right)$ has to be reached within $1 \mathrm{~min}$, considering the fact that the heating of joints at the beginning of movement takes approximately $5 \mathrm{~min}$. After this time, the temperature in joints and muscles rises due to the physical activity and do not need external heating [20]. From the results presented in Figures 10 and 11, it can be seen that the temperature $40^{\circ} \mathrm{C}$ was reached within $1 \mathrm{~min}$ by applying $3 \mathrm{~V}$ for EFL1 specimen, $2.5 \mathrm{~V}$ for EFL2 and EFL3 specimens, and $1.5 \mathrm{~V}$ for $\mathrm{EFH} 1, \mathrm{EFH} 2$, and EFH3 specimens. As far as compression orthopedic heated supports are concerned, all the developed and investigated structures can be used by applying the above mentioned voltages, however, the higher linear density of the conductive yarn requires lower voltage to reach the particular temperature which is an great an advantage. Moreover, unevenness of the temperature on the surface of specimens EFH2 and EFH3 is much lower when compared to the corresponding structures knitted with lower linear density conductive yarns. It means that the consumption of the expensive electro-conductive yarn in the knitted structure is reduced at least by two times without any negative influence on the heating properties.

\subsection{Stretch-temperature $(\varepsilon-T)$ characteristics}

Compression orthopedic supports are worn in a stretched mode in order to generate compression to a limb. Because of this purpose, elastomeric yarns are used in knitted structure and usually they are laid as inlay-yarns. Such structure gives the best compression generation. Compression is necessary in heated orthopedic supports too. So, the conductive yarns are used in such structures not as straight laid yarns but bent in the form of loop. It gives a possibility for support extension up to the required level without any damage to electro-conductive yarn.

The specimens were stretched in the levels or states of $10 \%$, $15 \%$, and $20 \%$ in order to find the influence of stretching on the temperature generation and for EFL1 specimen $2.5 \mathrm{~V}$ was applied, while 3.0 V for EFL2 and EFL3 and $1.5 \mathrm{~V}$ for all EFH group specimens. The surface temperature of the specimens was measured after every $10 \mathrm{~s}$ during the first minute of observation, and after every $20 \mathrm{~s}$ starting from the first minute until the end of experiment $(600 \mathrm{~s})$. The obtained results are presented in Figures 12 and 13. Dependence of the generated temperature on the time has logarithmic character (coefficient of determination $R^{2}$ vary in the ranges $0.882-0.965$ ).
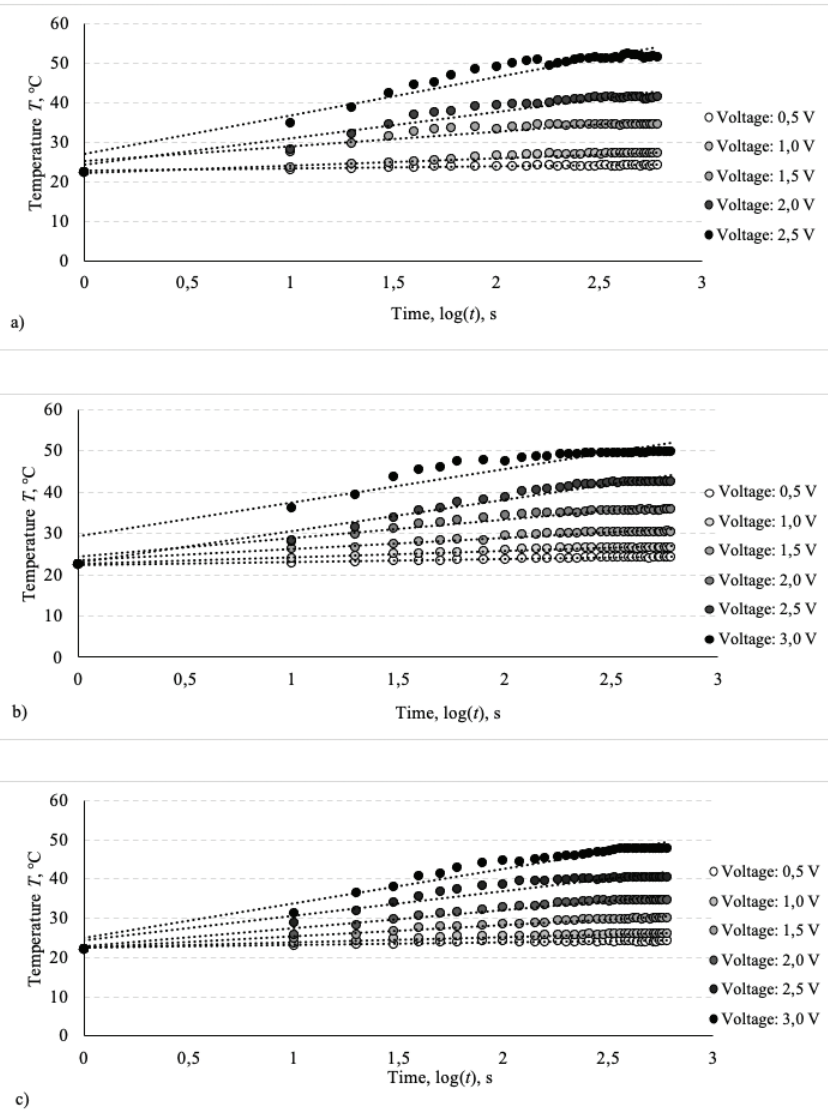

Figure 10. Temperature changes of EFL1 (a), EFL2 (b), and EFL3 (c) structured electro-conductive fabric during the $600 \mathrm{~s}$ period when applying different voltages. 

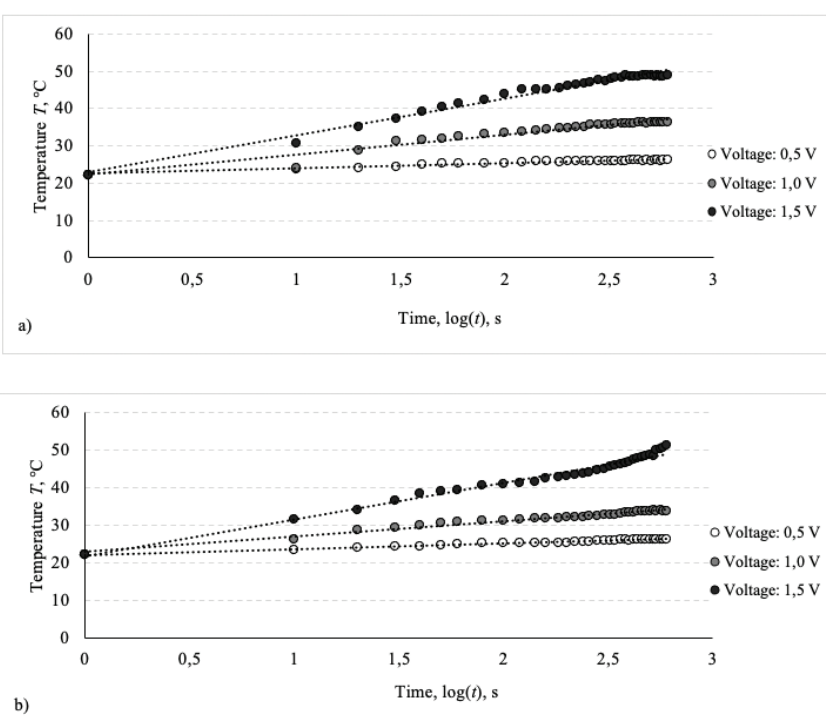

b)

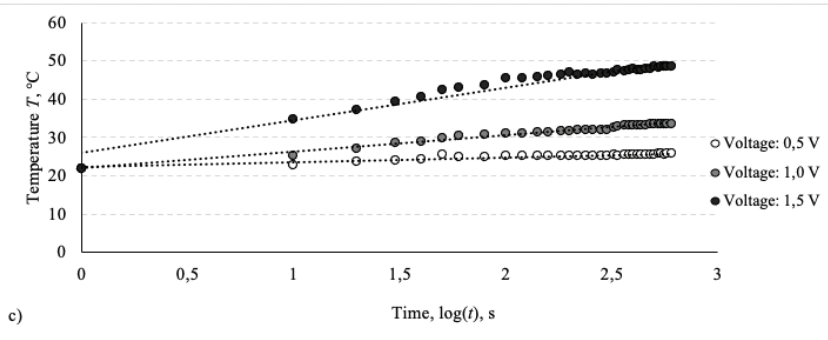

Figure 11. Temperature changes of EFH1 (a), EFH2 (b), and EFH3 (c) structured electro-conductive fabric during the $600 \mathrm{~s}$ period when applying different voltages.

It can be seen from the results presented in Figures 12 and 13 that the stretch of the compressive electro-conductive knitted fabric has a negative effect on the heat generation; however, the heat generation dynamics in both the non-stretched and stretched states has similar character during that time. It was found that $20 \%$ stretch has approximately $1^{\circ} \mathrm{C}$ lower influence on the final temperature (after $600 \mathrm{~s}$ period) of EFL1 specimen when compared to EFL2 and EFL3 structures and approximately $2^{\circ} \mathrm{C}$ lower influence on the final temperature of EFH1 specimens comparing to EFH2 and EFH3. The difference between specimen temperature in non-stretched and $10 \%$ stretched states after $600 \mathrm{~s}$ is $2.3^{\circ} \mathrm{C}$ for EFL $1,2.1^{\circ} \mathrm{C}$ for EFL2, and $2.2^{\circ} \mathrm{C}$ for EFL3, while this difference in nonstretched and $20 \%$ stretched states is $4.0^{\circ} \mathrm{C}, 5.2^{\circ} \mathrm{C}$, and $5.5^{\circ} \mathrm{C}$, respectively. For EFH group structures, the difference between temperatures in non-stretched and $10 \%$ stretched states is $1.3^{\circ} \mathrm{C}$ for $\mathrm{EFH} 1$, while $1.9^{\circ} \mathrm{C}$ for $\mathrm{EFH} 2$ and $2.1^{\circ} \mathrm{C}$ for $\mathrm{EFH} 3$, and for non-stretched and $20 \%$ stretched states, it is, accordingly, $2.2^{\circ} \mathrm{C}, 3.9^{\circ} \mathrm{C}$, and $4.4^{\circ} \mathrm{C}$. These differences can be explained by increase in area of the specimen due to stretching, while amount of the electro-conductive yarn in the sample remains the same. The amount of electro-conductive yarn used in the pattern repeat of the sample plays not high but significant role on the heat after stretching, while influence of distribution of the electro-conductive yarn in the pattern is insignificant, temperature values vary in the ranges of error.

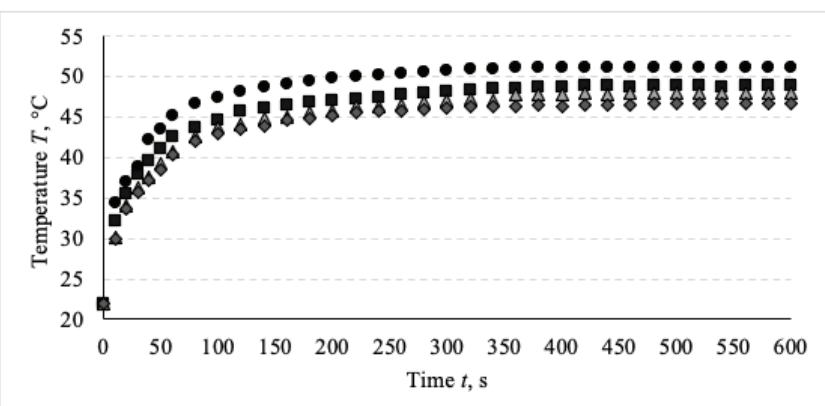

a) $\bullet 0 \%-10 \% \Delta 15 \% \diamond 20 \%$
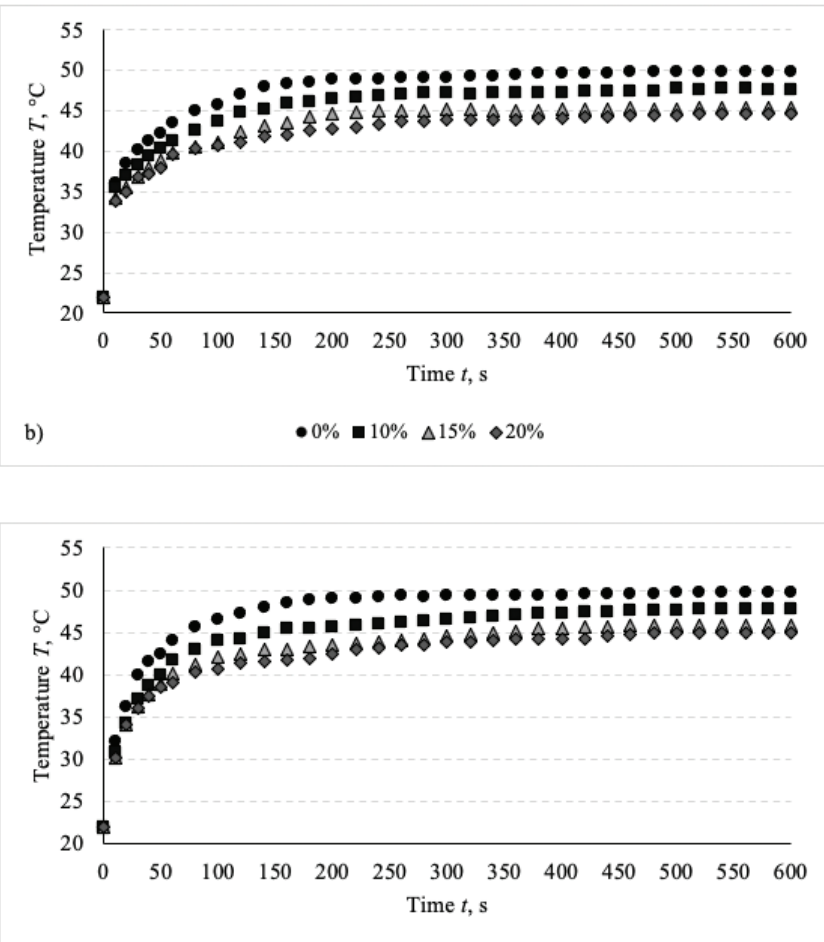

c)

$\bullet 0 \%-10 \% \Delta 15 \% \diamond 20 \%$

Figure 12. Temperature changes of EFL1 (a), EFL2 (b), and EFL3 (c) structured electro-conductive fabric during the $600 \mathrm{~s}$ period at different stretch level.

However, much more important is the period up to $300 \mathrm{~s}$, since heat therapy usually is applied for 3-5 min at the beginning of movement. The tendency of temperature differences between non-stretched and stretched EFL and EFH specimens

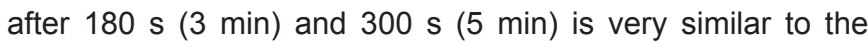
situation after $600 \mathrm{~s} .10 \%$ stretch caused $2.6^{\circ} \mathrm{C}$ decrease of EFL1 specimen temperature, $2-2.4^{\circ} \mathrm{C}$ decrease of EFL2, and 2.8-3. $4^{\circ} \mathrm{C}$ decrease of EFL3 structures temperature when compared with their non-stretched state. For EFH group, $10 \%$ stretch caused $1.4-1.5^{\circ} \mathrm{C}$ decrease of EFH1, $1.7-1.8^{\circ} \mathrm{C}$ decrease of $\mathrm{EFH} 2,1.8-2^{\circ} \mathrm{C}$ decrease of $\mathrm{EFH} 3$ temperature on comparing with non-stretched state. $20 \%$ stretch caused the following temperature decrease after $180 \mathrm{~s}$ and $300 \mathrm{~s}$ period - for EFL1, respectively, $5.5^{\circ} \mathrm{C}$ and $4.6^{\circ} \mathrm{C}$, for EFL2 $6^{\circ} \mathrm{C}$ and $5.3^{\circ} \mathrm{C}$, for EFL3 $-6^{\circ} \mathrm{C}$ and $5.5^{\circ} \mathrm{C}$; for EFH1 $-2.1^{\circ} \mathrm{C}$ and $2^{\circ} \mathrm{C}$, for $\mathrm{EFH} 2-3.9^{\circ} \mathrm{C}$ and $4.1^{\circ} \mathrm{C}$, for $\mathrm{EFH} 3-4.3^{\circ} \mathrm{C}$ and $4.2^{\circ} \mathrm{C}$. The required heating temperature is $40^{\circ} \mathrm{C}$ and higher, so it is important to note when this temperature is reached by 

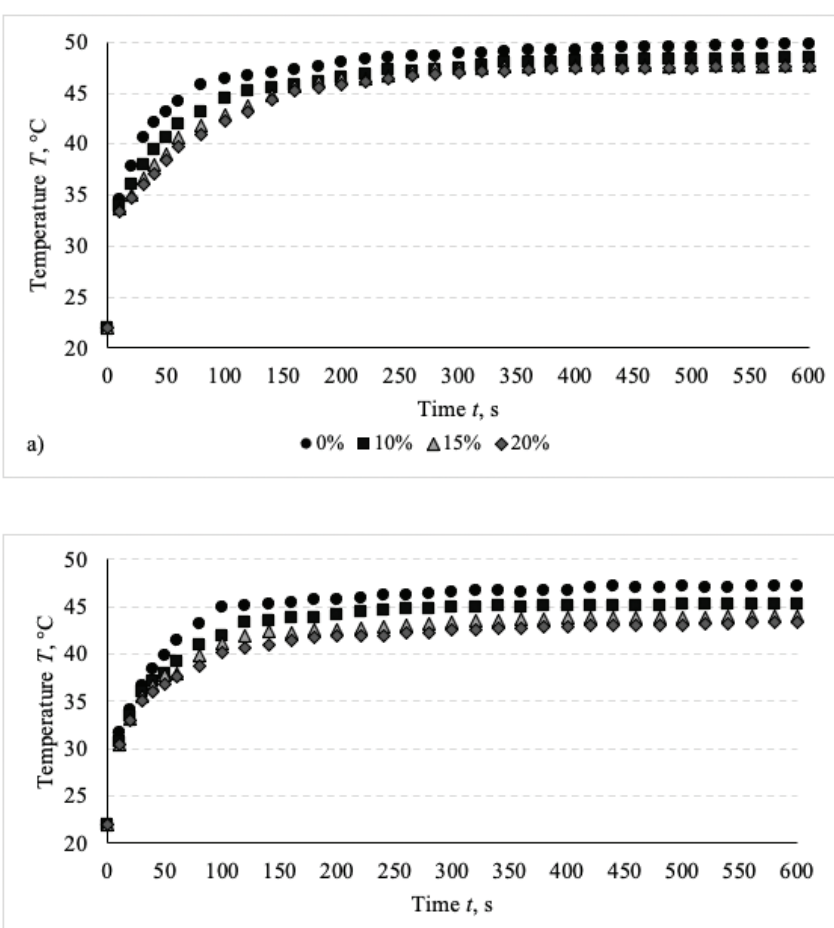

b) - $0 \%-10 \% \Delta 15 \% \triangleleft 20 \%$

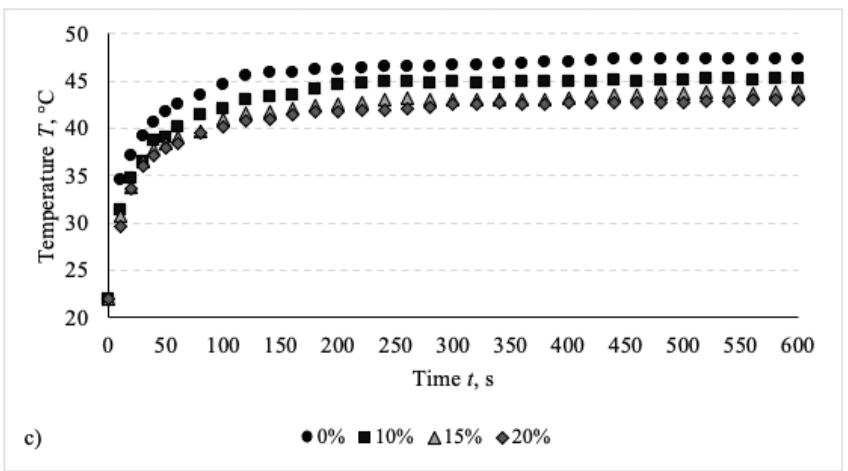

Figure 13. Temperature changes of EFH1 (a), EFH2 (b), and EFH3 (c) structured electro-conductive fabric during the $600 \mathrm{~s}$ period at different stretch levels.

applying a particular voltage and stretch of the compression structure. By applying $1.5 \mathrm{~V}$ voltage, EFH1 reaches $40^{\circ} \mathrm{C}$ temperature in non-stretched state in approximately $30 \mathrm{~s}$, while $\mathrm{EFH} 2$ and $\mathrm{EFH} 3$ it is approximately $60 \mathrm{~s}$. It is clear that when the amount of the conductive yarn used is increased twice in the knitted structure speeds the heating process by two times approximately. Further, ,specimens of the EFH group reached $40^{\circ} \mathrm{C}$ temperature in $50-60 \mathrm{~s}$ in $10 \%$ stretched state, and in $20 \%$ stretched state it is in $100 \mathrm{~s}$. Similar situation also was observed for EFL group specimens - the $40^{\circ} \mathrm{C}$ temperature limit was reached 20-40 s later for specimens in the stretched form.

The obtained results demonstrate that stretch used to generate compression of the orthopedic support on a limb has a negative effect on temperature generation; moreover, it has influence not only on temperature, but also on the time when the required temperature is reached. The influence of stretch on temperature changes of EFH group specimens knitted with higher linear density of electro-conductive yarn (235 tex) is slightly lower than of the EFL group specimens knitted with relatively low linear density electro-conductive yarns (66 tex). The positive result is that dynamics of temperature changes in non-stretched and stretched state are very similar, i.e. relatively stable temperature is reached at the same time in both nonstretched and stretched states. Therefore, the influence of stretch on heat changes has to be taken into account at the stage of development of a new compression heated support.

\section{CONCLUSION}

The combined half-Milano rib knitted structure proposed for compressive heated orthopedic supports, has an advantage as the electro-conductive yarn (silver coated polyamide which is very sensitive for mechanical abrasion) is used as the ground yarn in single jersey courses and is plated by PA6.6 yarn. As it was expected, the highest temperature was generated on the surface of the specimens with higher insertion of the conductive yarns in the knitting pattern - in each single jersey course of the half-Milano structure. When conductive yarn is laid with greater distance, temperature unevenness appears on the surface of the knit and this unevenness is higher for the fabrics with lower linear density conductive yarn.

All the presented electro conductive knitted structures can be used for heated orthopedic compression supports; however, the higher linear density of the conductive yarn requires lower voltage to reach the required $40^{\circ} \mathrm{C}$ temperature. In all investigated cases, temperature of the heated specimens rises very quickly during the first minute, but later on this rise becomes slow for all the voltages applied, until it reaches the constant value. The relatively stable $40^{\circ} \mathrm{C}$ heating temperature was reached in 30-60 s depending on specimen and voltage applied.

It was found that the stretch of the specimen has negative effect on the heat generation: $10 \%$ stretch caused approximately $2-2.5^{\circ} \mathrm{C}$ temperature decrease for specimens knitted by using 66 tex electro-conductive yarn (EFL), and approximately 1.5$2^{\circ} \mathrm{C}$ temperature decrease for specimens with 235 tex electroconductive yarn (EFH) when compared with corresponding nonstretched specimens. While $20 \%$ stretch caused approximately $4-6^{\circ} \mathrm{C}$ temperature decrease for EFL and $2-4.8^{\circ} \mathrm{C}$ decrease for $\mathrm{EFH}$ group specimens in comparison to non-stretched state. Also, the $40^{\circ} \mathrm{C}$ temperature due to stretch was reached 20-40 s later when compared to non-stretched specimens.

\section{ACKNOWLEDGMENTS}

This research was supported by the Research and Innovation Fund of Kaunas University of Technology (project grant No. PP59/2005). 


\section{References}

[1] Xie, J., Miao, M., Jia, Y. (2020). Mechanism of electrical conductivity in metallic fiber-based yarns. Autex Research Journal, 20(1), 63-63.

[2] Ali, A., Baheti, V., Militky, J., Khan, Z., Gilani, S. Q. Z. (2018). Comparative performance of copper and silver coated stretchable fabrics. Fibers and Polymers, 19(3), 607-619.

[3] Ehrmann, A., Blachowicz, T. (2017). Conductive yarns, fabrics, and coatings. In: Examination of textiles with mathematical and physical methods. Springer, Cham, pp. 13-29.

[4] Šahta, I., Baltina, I., Baribina, N., Blums, J. (2014). Selection of conductive yarns for knitting an electrical heating element. High performance and optimum design of structures and materials, 137, 91-102.

[5] Hwang, P. W., Chen, A.-P., Lou, C.-W., Lin, J.-H. (2014). Electromagnetic shielding effectiveness and functions of stainless steel/bamboo charcoal conductive fabrics. Journal of Industrial Textiles, 44(3), 477-494.

[6] Bhat, N. V., Seshadri, D. T., Radhakrishnan, S. (2004). Preparation, characterization, and performance of conductive fabrics: Cotton+ PANi. Textile Research Journal, 74(2), 155-166.

[7] Lee, J. Y., Park, D. W., Lim, J. O. (2003). Polypyrrolecoated woven fabric as a flexible surface-heating element. Macromolecular Research, 11(6), 481-487.

[8] Guo, L., Sandsjö, L., Ortiz-Catalan, M., Skrifvars, M. (2020). Systematic review of textile-based electrodes for longterm and continuous surface electromyography recording. Textile Research Journal, 90(2), 227-244.

[9] Droval, G., Glouannec, P., Feller, J. F. (2005). Simulation of electrical and thermal behavior of conductive polymer composites heating elements. Journal of Thermophysics and Heat Transfer, 19(3), 375-381.

[10] Kayacan, O., Bulgun, E. Y. (2009). Heating behaviors of metallic textile structures. International Journal of Clothing Science and Technology, 21(2-3), 127-136.
[11] Hertleer, C., Meul, J., De May, G., Vasile, S., Odhiambo, S. A., et al. (2020). Mathematical model predicting the heat and power dissipated in an electroconductive contact in a hybrid woven fabric. Autex Research Journal, 20(2), 133139.

[12] Sparavigna, A. C., Florio, L., Avloni, J., Henn, A. R. (2010). Polypyrrole coated PET fabrics for thermal applications. Materials Sciences and Applications, 1(4), 253.

[13] Maity, S., Chatterjee, A., Singh, B., Sin, A. P. (2014). Polypyrrole based electro-conductive textiles for heat generation. The Journal of the Textile Institute, 105(8), 887-893.

[14] Hamdani, S. T. A., Potluri, P., Fernando, A. (2013). Thermomechanical behavior of textile heating fabric based on silver coated polymeric yarn. Materials, 6(3), 1072-1089.

[15] Ališauskiené, D., Mikučionienè, D., Milašiūtè, L. (2013). Influence of inlay-yarn properties and insertion density on the compression properties of knitted orthopaedic supports. Fibres \& Textiles in Eastern Europe, 6 (102), 7478.

[16] Muraliene, L., Mikucioniene, D., Laureckiene, G., Brazaitis, M. (2019). New approach to evaluation of orthopaedic supports compression properties. Journal of Industrial Textiles, 49(3), 352-364.

[17] Alisauskiene, D., Mikucioniene, D. (2012). Influence of the rigid element area on the compression properties of knitted orthopaedic supports. Fibres \& Textiles in Eastern Europe, 20(6A), 103-107.

[18] Mikučioniené, D., Milašiūtè, L. (2017). Influence of knitted orthopaedic support construction on compression generated by the support. Journal of Industrial Textiles, 47(4), 551-566.

[19] Paulauskas, H., Baranauskiene, N., Wang, J., Mikučioniené, D. (2020). Local knee heating increases spinal and supraspinal excitability and enhances plantar flexion and dorsiflexion torque production of the ankle in older adults. European Journal of Applied Physiology, doi: 10.1007/s00421-020-04449-8.

[20] Brazaitis, M., Paulauskas, H., Eimantas, N., Daniuseviciute, L., Volungevicius, G., et al. (2019). Motor performance is preserved in healthy aged adults following severe wholebody hyperthermia. International Journal of Hyperthermia, 36(1), 65-74. 